REGARDS

SUR L'ECONOMIE ALLEMAND

BULLETIN ECONOMIQUE DU CIRAC
Regards sur l'économie allemande

Bulletin économique du CIRAC

$70 \mid 2005$

Varia

\title{
Société : la générosité des Allemands
}

Isabelle Bourgeois

\section{OpenEdition}

Journals

Édition électronique

URL : http://journals.openedition.org/rea/2233

DOI : 10.4000/rea.2233

ISBN : 978-2-8218-0836-2

ISSN : 1965-0787

Éditeur

CIRAC

Édition imprimée

Date de publication : 1 mars 2005

Pagination : $37-38$

ISSN : 1156-8992

Référence électronique

Isabelle Bourgeois, « Société : la générosité des Allemands », Regards sur l'économie allemande [En ligne], 70 | mars 2005, mis en ligne le 16 décembre 2008, consulté le 15 septembre 2020. URL : http:// journals.openedition.org/rea/2233

Ce document a été généré automatiquement le 15 septembre 2020.

(C) CIRAC 


\title{
Société : la générosité des Allemands
}

\author{
Isabelle Bourgeois
}

\section{0 millions $€$ de dons privés pour les victimes du tsunami}

1 Après le tsunami de la fin 2004, l'Allemagne a fait preuve d'une générosité hors pair. Si le gouvernement fédéral a décidé de débloquer quelque 500 millions $€$, les ménages ont fait don de quelque 370 millions $€$, selon une enquête effectuée par l'agence AP et publiée le 11 janvier 2005. La Croix Rouge allemande vient en tête des organismes collecteurs (près de 75 millions $€$ ), suivie d'Aktion Deutschland hilft (ADH), de l'UNICEF, de l'antenne allemande de Médecins sans frontières, ou des œuvres catholiques (Caritas) et protestantes (Diakonie), sans oublier les comptes ad hoc créés à l'initiative de la télévision publique ZDF ou du quotidien Bild. La générosité traditionnellement plus élevée en période de Noël ne suffit pas à expliquer ce record.

\section{La prise de conscience de la mondialisation}

La forte médiatisation du tsunami n'y est à l'évidence pas étrangère. Mais le volume des dons dépasse largement le produit des collectes antérieures réalisées lors de catastrophes ou événements exceptionnels, ainsi que le rappelle l'Institut de recherches sociales Deutsches Institut für soziale Fragen (www.dzi.de) : en 1990, les ménages avaient versé 60 millions $€$ pour «aider la Russie» (opération pilotée notamment par le quotidien Bild) ou 110 millions $€$ d'aide humanitaire au Kosovo en 1999. D'ordinaire, la proximité d'une catastrophe influe sur le volume des dons : c'est ainsi que 350 millions $€$ avaient été recueillis à l'été 2002, après les inondations dans l'est de l'Allemagne. Mais il semblerait, à en croire le sociologue Heinz Bude (Université de Kassel), que les liens touristiques étroits noués avec l'Asie du Sud aient rapproché cette région des préoccupations des Allemands, à quoi s'ajoute que «progressivement, 
nous prenons conscience $d u$ fait que nous vivons dans un monde globalisé» (Die Welt, 11-01-05).

\section{La bienfaisance, un 'marché' de 2,3 milliards $€$}

3 Quoi qu'il en soit, les aides aux victimes du tsunami n'ont d'extraordinaire que leur concentration sur un événement ponctuel. Leur volume est en effet à peu près équivalent au total des dons versés aux œuvres au cours du seul $3^{\mathrm{e}}$ trimestre 2004, soit 395,4 millions $€$, selon les estimations de l'Institut GfK et de l'instance d'autorégulation des ONG et œuvres sociales, le Deutscher Spendenrat (www.spendenrat.com), qui viennent de réaliser conjointement une étude sur le comportement des Allemands en la matière («Bilanz des Helfens »). Les trois quarts des dons (2,3 milliards $€$ en 2004, soit autant qu'en 2003) sont collectés par des organismes d'aide humanitaire et sociale, les autres secteurs étant réduits à la portion congrue : protection de l'environnement $(3,7 \%)$, des animaux $(3,6 \%)$ ou du patrimoine $(3,5 \%)$.

4 L'élan donateur s'explique par l'histoire de l'Allemagne. "Les Allemands de la génération d'après-guerre, ceux qui ont contribué au retour de la prospérité, désirent en restituer une part à la société", explique Christoph Mecking, président de la Fédération des fondations Bundesverband Deutscher Stiftungen. Mais ils souhaitent également garder un certain contrôle de l'utilisation de leurs dons puisqu'ils «impliquent leurs valeurs" (Die Welt, 05-12-04). C'est ainsi qu'ils préfèrent les grands organismes agréés, comme le confirme la Fédération allemande du fundraising: $1 \%$ seulement des organismes se partagent $85 \%$ des fonds collectés (www.fundraisingverband.de). La concurrence est rude sur le 'marché' caritatif, incitant cette fédération à créer une centre de formation: la Fundraising Akademie, pour contribuer à réguler ce marché en le professionnalisant.

\section{La générosité reflète l'organisation du secteur de la bienfaisance}

5 Bien sûr, le régime fiscal entretient la générosité des Allemands (comme des Français, au demeurant) ; le montant des dons ne cesse de progresser depuis 1995, passant de $80 €$ en moyenne par personne à $101 €$ à la fin 2004, selon l'institut TNS Emnid. Mais elle s'explique aussi par les valeurs de solidarité au fondement de l'économie sociale de marché (dont sont plus proches, il est vrai, les générations d'après-guerre, les plus de 50 ans constituant une large moitié des donateurs), et plus encore par le haut degré d'auto-organisation de la société civile (expression du principe de subsidiarité) qui fait que nombre d'activités sociales ou de bienfaisance ne sont pas exercées par l'Etat, mais par des organismes privés. La structure des dons par destination en est le reflet: les Allemands privilégient le secours aux malades et handicapés, l'aide humanitaire exceptionnelle ne venant qu'en seconde position, avant l'aide à l'enfance. Depuis 1999, on constate en outre l'essor de l'aide humanitaire et au développement. Le recul relatif de la 'part de marché' des œuvres caritatives confessionnelles, tombée de $31 \%$ à $22 \%$ au fil de la décennie (Emnid), reflète bien cette restructuration des flux.

6 Si la générosité des ménages est constante dans le temps, insensible au tassement de leurs revenus disponibles, la 'branche' caritative regrettait encore, à l'approche de la période de Noël, une certaine propension au nombrilisme. Le tsunami aura provoqué 
un transfert des réflexes de solidarité de proximité à un espace désormais plus vaste : ce « village global » qu'entrevoyait voici 30 ans le sociologue des médias Mc Luhan. (IB)

INDEX

Mots-clés : bienfaisance, don, générosité, marché, Société 